\title{
O Que é uma Política e o Que é um Programa: uma Pergunta simples e até hoje sem RESPOSTA CLARA ${ }^{1,2}$
}

Antonio Lassance ${ }^{3}$

\section{UM DEFEITO DE FÁBRICA À ESPERA DE UM RECALL}

Um espectro ronda desde sempre a administração pública: a dificuldade de se definir claramente o que é uma política pública e o que é um programa governamental. O problema é tão comum e crônico que praticamente passou a ser considerado parte da paisagem das políticas públicas. É uma espécie de defeito de fábrica à espera de um recall.

Ao longo dos últimos cinco anos, busquei entender esse problema na interação com centenas de dirigentes, gestores, analistas e assessores governamentais, das mais diferentes áreas e carreiras do serviço público. Fiz isso em uma série de entrevistas, como pesquisador; e em oficinas de trabalho e seminários de planejamento, na condição de assessor do Ipea ou de moderador (ou facilitador, como alguns preferem).

Em cursos diversos (análise de políticas públicas; avaliaçáo de programas; planejamento estratégico; mapeamento de atores e rastreamento de agendas; governança e gestáo), como professor ou orientador de servidoras e servidores no mestrado do Ipea ou na especialização da Escola Nacional de Administração Pública (Enap), desenvolvi um experimento muito simples para aferir a facilidade ou dificuldade de cada participante em identificar e distinguir política de programa.

O exercício consistia, muito simplesmente, em pedir para que cada cursista escolhesse uma política ou um programa, a ser analisado ao longo do curso, e começasse dizendo a que problema de política pública o caso em questấo se referia.

As escolhas começavam com dúvidas do tipo: "posso considerar o 'caso y' como uma política?" ou "o 'caso x' é política ou programa?".

O denominador comum era e ainda é, salvo raras exceçóes, receber respostas que embaralhavam políticas, programas e instrumentos de políticas públicas. O desacerto vinha de pessoas das mais diversas trajetórias - veteranas ou novatas no serviço público; do quadro ou comissionadas - algumas já tendo passado por secretarias executivas, secretarias de área, presidências, diretorias, chefias ou assessorias de estatais e autarquias.

Algumas opções aventavam políticas que sequer estavam institucionalizadas; não existiam, a não ser como abstraçóes que brotavam de uma necessidade sentida por quem respondia, como personagens à procura de um enredo. "Mas essa política existe?", perguntava o professor para validar

1. DOI: http://dx.doi.org/10.38116/bapi27art7

2. A escrita deste artigo segue a diretriz de garantir o direito de acesso à informação em formatos abertos, de melhor acessibilidade e em linguagem de fácil compreensão. Essa diretriz está prevista tanto na Lei de Acesso à Informação (art. 50 da Lei no 12.527/ 2011) quanto nos princípios dos movimentos de ciência aberta (open science) e pela linguagem clara (plain language). Agradeço à Anna Paula Feminella, da Escola Nacional de Administração Pública (Enap), pelas orientações dadas neste sentido.

3. Técnico de planejamento e pesquisa na Diretoria de Estudos e Políticas do Estado, das Instituições e da Democracia (Diest) do Ipea. 
ou não o caso. "Ainda não”. "Não existe, mas deveria existir!”. "Este é o problema: existe, mas ninguém percebe desse jeito” - eram algumas das respostas curiosas e angustiadas.

Ao longo do desenvolvimento dos exercícios, percebeu-se que as pessoas foram ensinadas a conviver com a babel, a não prestar muita atenção nisso e a reproduzi-la continuamente.

Por exemplo, uma das "definiçóes" mais antigas e famosas do que é uma política, na verdade, é um não conceito, uma indefinição. Em seu jogo de palavras que dizia tudo sem esclarecer absolutamente nada, Dye (1972, p. 2) cravava que política pública é "tudo aquilo que um governo escolhe fazer ou deixar de fazer".

Não importou muito a confissão de Dye (1972, p. 13) de que seu livro “desencorajava discussóes acadêmicas em torno de uma definição de política pública” que fosse mais precisa e que políticas e programas poderiam ser tratados como sinônimos, com diferenças meramente de escala. Até hoje, muitos dos manuais que "explicam" o que são políticas não só reprisam o conceito de Thomas Dye como o consideram um dos melhores, mais simples e direto entre todos (Howlett e Cashore, 2014; Cairney, 2012).

No entanto, a baixa assertividade para delimitar as distinções e costurar a relação entre políticas e programas, de modo estruturado e melhor aparelhado, vai além do problema conceitual. É comum que muitas políticas e programas governamentais surjam como descrito pela "teoria da lata de lixo" (garbage can theory) (Cohen, March e Olsen, 1972), ou seja, soluçóes em busca de um problema, e não problemas que orientem a construção de soluções.

A lata de lixo tornou-se mainstream não exatamente com essa embalagem pouco convidativa, mas sob o eufemismo das "boas práticas". Elas são produtos de prateleira que trazem consigo alguns problemas típicos.

O primeiro deles é que soluçóes baseadas em supostas boas práticas são opções assumidas por dirigentes e gestores com um grave viés de seleção. Experiências que tiveram bons resultados em um estado ou município não necessariamente servem a outro, se os problemas e as variáveis de contexto forem muito diferentes. Quando herdadas de modelos internacionais, as diferenças socioeconômicas e político-institucionais são abissais. A começar, a capacidade de financiamento dessas soluçóes no longo prazo é muito diferente.

Apesar de as boas práticas serem exemplos muito ricos e inspiradores, um traço usual à maioria delas é sua falta de sistematização. Muitos dos seus registros são focados nas realizações, e não no processo de formulação, desenho, planejamento e implementação da política. Essas realizaçôes ganham fama baseadas em notícias, relatos fragmentados e na troca de experiências in loco.

Boas práticas são mais pacotes de novidades, às vezes prototipadas, do que programas devidamente testados e avaliados. São respostas parciais que estão longe de serem soluçôes integradas que incidam sobre o problema central da política.

Para incorporar as novidades, a saída usual costuma ser a de se criar mais estruturas de governança e gestão e de se demandar mais orçamento para, assim, abrir o leque de ofertas ou contratar mais produtos de prateleira.

As ofertas de prateleira vão se acumulando e estimulam sobreposiçóes, contradições e uma pulverização tão grande das supostas soluçóes que tornam os programas muito mais fragmentados 
do que já eram. Pior, criam um cipoal de projetos e atividades desconectados dos problemas centrais, o que significa dizer desplugados das políticas.

A imagem da colcha de retalhos é recorrente nos relatos tanto de quem formula políticas quanto de quem implementa programas. Ambos reputam a isso elevados custos de coordenação, dubiedades, ambiguidades e entrechoque de estruturas, seja entre órgãos diferentes ou dentro de unidades de um mesmo órgão.

Ao fim, a solução se transforma em parte do problema e a babel agora reverbera por um labirinto de programas, unidades gestoras, normativos, urgências mal acolhidas e frustraçóes.

\section{COMO SAIR DO IMPASSE?}

A opção mais adequada para superar tal situação seria, conforme a recomendação essencial de Carol Weiss (até hoje, considerada a maior referência em avaliação de políticas e programas), "a aplicação do conhecimento das ciências sociais e de metodologia” (Weiss, 1998, p. 3). Tão simples quanto isso. Esse lastro é necessário para induzir políticas baseadas em evidências, sustentadas em teoria, aderentes a critérios transparentes e que façam algum sentido.

A questão é um pouco mais complexa quando se constata que alternativas mais consistentes exigem de desenvolvedores de políticas públicas (policymakers) alguma desenvoltura para tratar o assunto de modo mais estruturado e melhor aparelhado, em seu ferramental teórico, metodológico e técnico.

Uma burocracia qualificada em análise ex ante e desenho de políticas, atenta aos princípios de equidade, transparência, responsividade e amparada também por uma relação mais afinada com os órgãos de controle (quando alinhados e qualificados nessa mesma direção), favoreceria uma racionalidade que servisse como uma espécie de contrapeso republicano, com algum poder de resistência ao círculo vicioso das soluçóes de prateleira encomendadas e vendidas como elixires.

Ainda mais desafiador é tornar a relação entre políticos e burocratas também mais assertiva. O dilema weberiano secular (Weber, 1999) entre a ética da convicção e a ética da responsabilidade, repaginado como a relação entre um governo de estranhos (Heclo, 1977; Carpenter, 2020), permanece intacto e importante (Maranto, 2005). Enquanto políticos são guardióes da convicção, burocratas são guardiôes da responsabilidade. Vivem mundos distintos, com gramáticas, temporalidades e urgências clivadas.

Como superar esse impasse? Com referenciais bem fundamentados e mais amigáveis à formulação e à construção de políticas e programas; usando o planejamento como processo de diálogo, pactuação e transparência das organizaçóes (e não mera programaçáo burocrática); direcionando políticas e programas mais claramente ao público - há políticas e programas que até hoje imaginam que suas entregas se referem a coisas, e não a pessoas; propondo metas e ciclos de maturação bem definidos.

Esses são requisitos que poderiam interessar a políticos, burocratas e, certamente, ao público. De quebra, poderiam evidenciar quem não se interessa ou não resiste a tais avanços.

\section{O QUE É UMA POLÍTICA E UM PROGRAMA? A TEORIA RESPONDE}

Teoria, qualquer que seja ela, é uma explicação acerca do comportamento de um problema. Além de explicar o passado, uma teoria supóe uma expectativa de resultados factíveis de serem antecipados caso as circunstâncias de ocorrência se repitam. 
Teoria é essencial para encontrar uma explicação sobre problemas de políticas públicas. Mais ainda para se encontrar soluçôes mais bem ajustadas. Essa possibilidade só ocorre, de modo efetivo, nos programas e, mais exatamente, em ações e projetos - portanto, no âmbito da gestão.

Supóe-se que, sob determinadas circunstâncias e mediante um sequenciamento lógico de insumos e processos, seja possível estimar metas de produtos, resultados e impactos que viabilizem os objetivos da política, fechando um longo ciclo que começa na estratégia e termina com os impactos de longo prazo. A isso se chama teoria do programa.

A gênese dessa abordagem se vale de teorias, metodologias e técnicas aprimoradas em um longo processo de aprendizado que remonta, entre outras, à teoria de sistemas (Easton, 1953), aos acúmulos da comunidade de avaliaçáo (Vedung, 1997; Weiss, 1998), ao planejamento estratégico orientado por objetivos (Ziel-Orientierte Projekt Planung - ZOPP), ao planejamento estratégico situacional (Matus, 2007) e ao uso de modelos lógicos (Cassiolato e Gueresi, 2015; Newcomer, Hatry e Wholey, 2015).

Daí em diante, usar teorias para o desenho de programas tornou-se uma abordagem consolidada entre a comunidade de especialistas em avaliação (Weiss, 1998; Vedung, 1997; Cassiolato e Gueresi, 2015; Newcomer, Hatry e Wholey, 2015; Ferreira, Cassiolato e Gonzalez, 2015; Ipea, 2018).

Como qualquer outro tipo de teoria, supóe-se que uma teoria do programa tenha como base uma formulação e um método de análise fundamentados por evidências submetidas ao escrutínio público, com o amparo de uma comunidade de especialistas dentro e fora dos governos.

Ao se usar tal referência, aproveita-se da expertise desenvolvida nas mais diversas áreas de análise de políticas públicas. Mais importante, assume-se o compromisso de que políticas e programas nasçam desenhados com transparência e sejam monitorados e avaliados regularmente (Garcia, 2015; Cardoso Junior, 2015).

Apesar da origem e uso comum a campos distintos, um dos desafios é romper o divórcio entre os campos de análise ex ante de políticas públicas, avaliação ex post e planejamento estratégico, comum entre analistas, salvo em equipes multidisciplinares que atuam conjuntamente (como ocorre com o Ipea). ${ }^{4}$

A base desse desenho é a identificação precisa de um problema central de política pública e dos problemas que são suas causas raízes. Embora essa constatação seja relativamente trivial, fazê-lo não é algo simples. A integração de abordagens é crucial.

A dificuldade em identificar um problema central e o público diretamente associado a ele é a peça-chave do "defeito de fábrica" das políticas e programas. Quando essa definição elementar é negligenciada, o amadorismo ou as soluçóes de prateleira apresentam-se como maus substitutos.

A base da definição de um problema central é a explicação de sua lógica e a estilização de suas causas e consequências. Um problema central é gerado por causas raízes que lhe são, obviamente, anteriores, e revela consequências que não existiriam caso esse não fosse, de fato, um problema central.

4. Um dos exemplos dessa perspectiva de integração de abordagens está em trabalhos realizados pelos pesquisadores Martha Cassiolato e Ronaldo Garcia, do Ipea. Esses trabalhos foram aplicados a vários órgãos governamentais ao longo de décadas. Alguns dos resultados desses estudos, realizados com pesquisadores com os quais Cassiolato e Garcia se reuniram e compartilharam seu aprendizado, são citados ao longo deste artigo. 
Conforme lembrava Carlos Matus, a definição de um problema central e a explicação de suas causas não são mero diagnóstico (Matus, 2007; 1993). É um exercício lógico que revela não apenas características (uma lista), mas também o encadeamento do problema.

Uma política pública nasce justamente a partir do confronto entre a lógica de um problema decifrado e o propósito deliberado de um ator do planejamento que tenha capacidade e autoridade para agir sobre esse problema (Matus, 1989).

As definições estratégicas elegem problemas e fazem escolhas ("apostas") de tratamento sobre um conjunto hierarquizado de problemas (Matus, 2007; De Toni, Salerno e Bertini, 2008). Ao ser atacado nesses pontos críticos, o problema central sofrerá alteraçóes, sendo mitigado ou superado em suas consequências mais danosas. Isso caso a teoria do programa esteja correta.

\section{ENFIM, UM CONCEITO FUNDAMENTADO TEORICAMENTE}

Com tal aparato teórico-metodológico, é possível construir uma distinção mais clara entre políticas e programas.

Política pode então ser conceituada como

uma proposta institucionalizada de solução de um problema central, orientada por uma concepção. Podemos chamar essa concepção de teoria, quando for fundamentada por uma explicação lógica, ou seja, quando for capaz de ligar causas e consequências explicativas (isto é, que respondam o porquê desse problema central).

Dizer que a solução é institucionalizada é mais exato que dizer que a política é algo que um governo faz ou deixa de fazer. A política se estabelece antes do fazer; ela antecede a ação. A política nasce como regra, como concepção que define um curso para a ação. A institucionalização é um conceito essencial à definição de política também porque esse processo perpassa outros Poderes. Afinal, institucionalizar regras de política requer (em democracias, obviamente) a aprovação legislativa e aquiescência judiciária quanto à sua legalidade.

Definidas a partir de uma estratégia, isto é, pela escolha de problemas cruciais a serem atacados simultaneamente ou conforme uma hierarquia, as políticas são implementadas por meio de programas.

Programa é, precisamente,

a solução dada a cada um dos problemas causais que explicam o problema central da política e que foram julgados cruciais por uma estratégia concebida para cercá-lo, enfrentá-lo e superá-lo.

A necessidade de uma política ter normalmente mais de um programa se deve ao fato de que há causas que correm em raias próprias e precisam ser trabalhadas em paralelo. Problemas de políticas públicas são, em geral, complexos e multicausais. Dificilmente são resolvidos de forma serial. ${ }^{5}$

Não existem políticas sem programas, e vice-versa, mas perceber a relação que vários programas têm com um mesmo problema central é a chave para desenhar políticas integradas. Elas só podem ser integradas se o forem por seus programas. 
A política é o ambiente macro da solução, em que se deveria ter uma visão mais ampla mirando a efetividade (os impactos). Por isso as políticas são soluçóes cuja maturação demanda continuidade no longo prazo, visto que nascem associadas a um macroproblema considerado como central.

Os programas são o ambiente micro, ou seja, são o espaço de detalhamento no qual se consegue, com maior refinamento, focalizar o público-alvo, estimar recursos, escolher indicadores e definir metas.

Metas significam expectativas de mudança de indicadores com entregas almejadas, em seus devidos prazos, de produtos (curto prazo), resultados (médio prazo) e impactos (longo prazo). Mais uma vez, é a teoria do programa que também preside a escolha de indicadores e metas.

São os programas que tornam o problema central da política melhor "manuseável”. Eles são frentes de trabalho que atuam sobre partes menores. Mas o que se espera de uma política abrangente e, ao mesmo tempo, coerente, eficiente e efetiva é que essas frentes, que agem em paralelo, possam adiante produzir resultados sinérgicos, integrados.

\section{UM CRITÉRIO BÁSICO À ANÁLISE EXANTE}

A falha em distinguir políticas e programas gera toda uma espiral de consequências. É o primeiro de muitos problemas de políticas que já nascerão fragmentadas e inconsistentes e de programas com objetivos nebulosos, redundantes, ineficientes e inefetivos.

Uma abordagem mais assertiva poderia conferir um novo sentido, por exemplo, aos planos plurianuais (PPAs), que poderiam ser basicamente os instrumentos de definição das políticas de governo (e não de ministérios), com objetivos multissetoriais de superação de macroproblemas e associados à Estratégia Federal de Desenvolvimento (EFD), prevista para projetar-se em um horizonte de doze anos (três PPAs - 2020-2031).

Dessa maneira, políticas de redução da desigualdade, desenvolvimento regional, promoção social, geração de emprego e renda, proteção à criança e ao adolescente, integração sul-americana, entre outras que estão referenciadas como objetivos e princípios constitucionalizados da República, se tornariam objetivos comuns a todas as áreas e, preferencialmente, passíveis de ultrapassar mais de um governo, inscrevendo-se como objetivos do Estado brasileiro.

O uso de uma metodologia concatenada contribuiria para amarrar melhor a relação entre a EFD e o PPA para definir macroprioridades governamentais, superando uma das lacunas que têm sido apontadas no planejamento governamental (Couto e Cardoso Junior, 2018).

Os programas, por sua vez, seriam o produto por excelência dos ministérios. Eles variariam conforme as prioridades de cada governo, mas seu desenho deveria incluir e atualizar metas plurianuais relacionadas a objetivos macro, com a previsão de entregas intermediárias (quatro anos) capazes de aferir a execução e efetividade do PPA e a consistência da estratégia nacional de longo prazo.

Uma clareza maior da relação entre políticas e programas também ajudaria a sepultar o debate que opõe, equivocadamente, universalização e focalização. Não existe focalização de política (Lassance, 2020). A focalização é sempre uma escolha contingente e estratégica feita por programas na definição do público-alvo específico ou priorizável, diante de uma dificuldade de se atender a um público mais amplo, de imediato. Enquanto programas focalizam porque incidem sobre causas 
distintas de um mesmo macroproblema, políticas reúnem esses públicos distintos (focalizados pelos programas) sob um guarda-chuva universalista.

Focalização feita em programa não desfaz o caráter universal de uma política, a exemplo do que se vê no Sistema Único de Saúde (SUS), na educação e na assistência social.

Outra dificuldade possível de ser superada ou pelo menos mitigada é a célebre indefinição entre o estratégico, o tático e o operacional. Em meio à ambiguidade, o estratégico foi a tal ponto banalizado que tornou-se quase inútil, até praticamente cair em desuso.

A rigor, seguindo uma teoria do programa, o estratégico está formulado no plano da política, portanto, diz respeito a um problema central. Os programas, embora decorram de uma decisão estratégica (é a estratégia que justifica a existência de um programa), são por excelência o espaço da tática, ou seja, da mobilização, do treinamento, do sequenciamento de processos e da programação orçamentária, do monitoramento e da avaliação de resultados.

O operacional, finalmente, ocorre no nível das açóes e dos projetos, sendo por excelência a dimensão da gestão, que diz respeito ao uso de insumos, na forma de fluxos (processos) e orientados a otimizar resultados (Lassance, 2015, p. 41).

Adotar essas separatrizes lógicas aperfeiçoaria a governança e daria mais autonomia à gestáo, além de deixar claras as esferas de responsabilização. A alta administração deveria dedicar-se exclusivamente a dar governabilidade à política e cuidar da governança, no que concerne às condiçóes para que os programas possam ser criados e implementados, cobrando resultados. Essa seria a função de presidentes, ministros, governadores e prefeitos, responsáveis por garantir decisóes que dependem do convencimento de outros atores de fora de sua organização, de outros governos e demais Poderes.

Dirigentes de secretarias cuidariam da governança de programas, sendo responsáveis por planejá-los, montá-los e comandá-los, atendendo a requisitos estratégicos, mas com a devida delegação e o compromisso de devolver resultados conforme o ciclo de maturação pactuado em cada programa. Por fim, seriam responsáveis por autarquias e empresas estatais que viabilizariam entregas de produtos e serviços.

A ausência de um pacto de delegação que respeite estritamente essas diferenças de papéis é uma lacuna que prejudica não apenas o aprimoramento do desenho de políticas e programas, mas também afeta toda a cadeia de governança, confunde e torna mais tensa a relação entre políticos e burocratas, introduz ineficiências e compromete a capacidade de que muito do que o serviço público oferece possa ser devida e criteriosamente avaliado.

Em suma, espera-se que a abordagem apresentada neste artigo se dissemine como critério básico à análise ex ante, sob o crivo dos pareceres de méritos a que todas as políticas devem se submeter, por força do Decreto no 9.191/2017 (Brasil, 2017).

Mais que isso, espera-se que a análise contribua para que tais incongruências latentes se tornem gritantes e evitáveis aos olhos de desenvolvedores de políticas públicas - de dirigentes e formuladores a gestores e burocratas de nível de rua.

Falhas dessa natureza podem ser fácil e antecipadamente detectadas pela análise ex ante, antes mesmo que qualquer programa mal desenhado seja iniciado e passe a consumir recursos públicos e dedicação de tempo de seus servidores. 


\section{REFERÊNCIAS}

BRASIL. Decreto no 9.191 , de $1^{\circ}$ de novembro de 2017. Estabelece as normas e as diretrizes para elaboração, redação, alteração, consolidação e encaminhamento de propostas de atos normativos ao presidente da República pelos ministros de Estado. Diário Oficial da União, Brasília, 3 nov. 2017. Disponível em: <https://outline.com/b96KF8>. Acesso em: 19 set. 2020.

CAIRNEY, P. Understanding public policy. London: Palgrave Macmillan, 2012.

CARDOSO JUNIOR, J. C. Monitoramento estratégico de políticas públicas: requisitos tecnopolíticos, proposta metodológica e implicaçóes práticas para a alta administração pública brasileira. In:

(Org). Planejamento Brasil século XXI: inovação institucional e refundação administrativa elementos para o pensar e o agir. Brasília: Ipea, 2015.

CARPENTER, D. P. The forging of bureaucratic autonomy: reputations, networks, and policy innovation in executive agencies, 1862-1928. New Jersey: Princeton University Press, 2020.

CASSIOLATO, M.; GUERESI, S. Como elaborar modelo lógico: roteiro para formular programas e organizar avaliação. In: CARDOSO JUNIOR, J. C.; CUNHA, A. dos S. (Org.). Planejamento e avaliação de políticas públicas. Brasília: Ipea, 2015. p. 297-332.

COHEN, M. D.; MARCH, J. G.; OLSEN, J. P. A garbage can model of organizational choice. Administrative Science Quarterly, v. 17, n. 1, p. 1-25, 1972.

COUTO, L. F.; CARDOSO JUNIOR, J. C. Governança orçamentária: transformaçóes e lacunas nas práticas de planejamento e orçamento no Brasil. Boletim de Análise Político-Institucional, v. 19, p. 75-82, 2018. Disponível em: <http://www.ipea.gov.br/portal/images/stories/PDFs/ boletim_analise_politico/181206_bapi_19_cap_10.pdf>.

DE TONI, J.; SALERNO, G.; BERTINI, L. Uma abordagem estratégica no planejamento de grupos: o Método Altadir de Planejamento Popular (MAPP). In: JACQUES, M. da G. C. et al. (Org.). Relaçóes sociais e ética. Rio de Janeiro: Ceps, 2008. Disponível em: <http://books.scielo. org/id/6j3gx/pdf/jacques-9788599662892-15.pdf>. Acesso em: 23 set. 2020.

DYE, T. R. Understanding public policy. New Jersey: Prentice Hall, 1972.

EASTON, D. The political system: an inquiry into the State of political science. New York: Alfred A. Knopf, 1953.

FERREIRA, H.; CASSIOLATO, M.; GONZALEZ, R. Uma experiência de desenvolvimento metodológico para avaliação de programas: o modelo lógico do programa segundo tempo. In: CARDOSO JUNIOR, J. C.; CUNHA, A. dos S. (Org.). Planejamento e avaliaçáo de políticas públicas. Brasília: Ipea, 2015. p. 333-376.

GARCIA, R. Subsídios para organizar avaliaçóes da ação governamental. In: CARDOSO JUNIOR, J. C.; CUNHA, A. dos S. (Org.). Planejamento e avaliaçáo de políticas públicas. Brasília: Ipea, 2015. p. 81-106.

HECLO, H. A government of strangers: executive politics in Washington. Washington: Brookings, 1977. 
HOWLETT, M.; CASHORE, B. Conceptualizing public policy. In: ENGELI, I.; ALLISON, C. R. (Ed.). Comparative policy studies: conceptual and methodological challenges. London: Palgrave Macmillan, 2014. p. 17-33.

IPEA - INSTITUTO DE PESQUISA ECONÔMICA APLICADA. Avaliação de políticas públicas: guia prático de análise ex ante. Brasília: Ipea, 2018. v. 1. Disponível em: <https://www. ipea.gov.br/portal/images/stories/PDFs/livros/livros/180319_avaliacao_de_politicas_publicas.pdf>. Acesso em: 23 set. 2020.

LASSANCE, A. Governança e gestão: uma radiografia dos gargalos do Estado brasileiro. Boletim de Análise Político-Institucional, n. 8, p. 39-44, 2015. Disponível em: <http:/www.ipea.gov.br/ portal/images/stories/PDFs/boletim_analise_politico/160218_boletim_analisepolitico_08_cap6.pdf>.

. Recuperaçáo ou reconstruçáo econômica? As opçóes do Brasil diante de uma crise sem igual e de soluções globais assimétricas. Brasília: Inesc, 2020. Disponível em: <https://www.inesc. org.br/wp-content/uploads/2020/09/Lassance-Recupera\%C3\%A7\%C3\%A3oOuReconstru\%C3 \%A7\%C3\%A3oEcon\%C3\%B4mica_Setembro-2020.pdf>. Acesso em: 25 set. 2020.

MARANTO, R. Beyond a government of strangers: how career executives and political appointees can turn conflict to cooperation. Lanhan: Lexington Books, 2005.

MATUS, C. Adeus, senhor presidente. Recife: Litteris, 1989.

Política, planejamento e governo. Brasília: Ipea, 1993. v. 1.

. O plano como aposta. In: GIACOMONI, J.; PAGNUSSAT, J. L. (Org.). Planejamento e orçamento governamental. Brasília: Editora Enap, 2007. v. 1.

NEWCOMER, K. E.; HATRY, H. P.; WHOLEY, J. S. Handbook of practical program evaluation. 4th ed. New York: John Wiley \& Sons, 2015.

SIMON, H. A.; NEWELL, A. Human problem solving: the state of the theory in 1970. American Psychologist, v. 26, n. 2, p. 145-159, 1971.

VEDUNG, E. Evaluación de políticas públicas y programas. Madrid: Mites, 1997.

WEBER, M. Economia e sociedade: fundamentos da sociologia compreensiva. Brasília: Editora UnB, 1999.

WEISS, C. Evaluation: methods for studying programs and policies. 2nd ed. New Jersey: Prentice Hall, 1998. 
